\title{
Kinerja Unit Crushing Plant Dalam Pengolahan Batu Andesit Di PT Bukit Asam, Tbk. Tanjung Enim, Sumatera
}

\section{(Performance of The Crushing Plant Unit In Andesit Rock Processing In PT Bukit Asam, Tbk. Tanjung Enim, South Sumatera)}

\author{
M. D. Amdi ${ }^{*}$, Mukiat $^{2}$, Y. B. Ningsih ${ }^{3}$ \\ ${ }_{1,2,3}$ Jurusan Teknik Pertambangan, Universitas Sriwijaya \\ *Korespondensi E-mail: meutiadianiamdi@gmail.com
}

\begin{abstract}
Abstrak
Meningkatnya pembangunan di kota Palembang beberapa tahun belakangan, membuat kebutuhan material konstruksi juga meningkat. Adanya andesit di daerah Tanjung Enim, seharusnya bisa menjadi pemasok batu split untuk daerah Palembang. Agar beton yang dihasilkan memiliki kualitas baik, ukuran batu split harus mengacu pada standar industri Indonesia. Untuk memenuhi standar tersebut, batu andesit hasil penambangan perlu diolah dan mengalami proses reduksi ukuran kemudian dianalisis agar memenuhi standar. Ukuran produk hasil pengolahan berkorelasi dengan kinerja unit crushing plant. Penelitian ini bertujuan untuk menganalisis produktivitas crushing plant dalam mengelola batu andesit. Penelitian dilakukan dengan mengamati kinerja unit crushing plant serta dilakukan analisis uji ayakan untuk mendapatkan nilai modulus kehalusan. Kemudian membandingkan nilai modulus kehalusan yang diperoleh dengan standar indonesia yang berkisar antara 6-7,10. Dari hasil penelitian diketahui produktivitas aktual unit crushing plant sebesar 142,1685 ton/jam dengan nilai ketersediaan alat kurang dari $64 \%$. Berdasarkan uji analisis ayakan, didapatkan nilai modulus kehalusan sebesar 7,66 dan belum memenuhi standar industri Indonesia. Hasil dari pemecahan sangat beragam sehingga pada pengolahan batu andesit diperlukan unit secondary crusher.
\end{abstract}

Kata kunci: Crushing plant, andesit, uji analisis ayakan.

\begin{abstract}
The increasing development in Palembang city in recent years has made the need for construction materials also increase. The existence of andesite in the Tanjung Enim area should have been able to supply split stone for the Palembang area. In order for the resulting concrete to have good quality, the size of the split stone must refer to the Indonesian industry standard. To meet these standards, andesite from mining needs to be processed and undergo a size reduction process then analyzed to meet the standard. The size of the processed product correlates with the performance of the crushing plant unit. This study aims to analyze the productivity of the crushing plant in managing andesite stone. The research was conducted by observing the performance of the crushing plant unit and analyzing the sieve test to obtain the modulus of fineness. Then compare the modulus of fineness obtained with the Indonesian standard, which ranges from 6-7.10. From the research results, it is known that the actual productivity of the crushing plant unit is 142.1685 tons / hour with a tool availability value of less than $64 \%$. Based on the sieve analysis test, it was found that the modulus of fineness was 7.66 and it did not meet the Indonesian industry standard. The results of the splitting are very diverse, so that in processing andesite stones a secondary crusher unit is required.
\end{abstract}

Keywords: Crushing plant, andesite, sieve analysis test.

\section{Pendahuluan}

Meningkatnya pembangunan di kota Palembang beberapa tahun belakangan membuat kebutuhan material konstruksi juga meningkat. Material konstruksi yang dibutuhkan salah satunya ialah split. Batu split digunakan sebagai campuran beton dengan proporsi terbesar dibandingkan semen dan pasir. Agar dihasilkan beton yang berkualitas, maka diperlukan ukuran batu split yang baik sebagai campuran beton.
Keterdapatan andesit di daerah Tanjung Enim dapat menjadi potensi sebagai pemasok batu split bagi daerah Palembang mengingat pasokan selama ini biasanya didatangkan dari luar Sumatera Selatan. Karena pembangunan yang pesat, dibutuhkan pula pasokan batu split yang lebih banyak untuk daerah Palembang.

Agar beton yang dihasilkan memiliki kualitas baik, ukuran batu split harus mengacu pada standar industri Indonesia 0052-80 dan juga Standar Nasional Indonesia (SNI) S-04-1989-F. 
Untuk memenuhi standar tersebut, batu split proses reduksi ukuran. Produk pengolahan harus dianalisis agar memenuhi standar tersebut.

Umumnya tahapan pekerjaan yang ada pada unit crushing plant dimulai dari hopper dan akan masuk tahapan pemilahan ukuran dengan menggunakan grizzly feeder. Setelahnya, material akan masuk pada tahap penghancuran pertama menggunakan jaw crusher. Kemudian, material akan masuk pada tahap penghancuran kedua dan material akan disimpan di gudang batu sekaligus memasuki tahapan penggerusan oleh cone crusher.

Produk akan dimuat dan diangkut oleh belt conveyor menuju vibrating screen (Putra, 2018). Berdasarkan tahapan tersebut, unit crushing plant biasanya memerlukan lebih dari satu alat peremukan sehingga produk pengolahan batu andesit lebih seragam dan spesifik sesuai dengan permintaan. Adanya unit peremukan lanjutan membuat produk batu andesit menjadi lebih kecil.

Proses penghancuran batuan ini harus dilakukan dengan bertahap, dikarenakan keterbatasan alat yang digunakan untuk menghancurkan batuan berukuran besar hingga menjadi berukuran kecil sesuai permintaan (Nugraha, 2018). Penentuan karakteristik batu

\section{Metode}

Lokasi penelitian (Gambar 1) ini berada di daerah Tanjung Enim, tepatnya di PT Bukit Asam, Tbk Unit Pertambangan Tanjung Enim, Sumatera Selatan pada bulan Maret 2020 sampai bulan April 2020. Saat ini unit pertambangan Tanjung Enim (UPTE) memiliki 3 site utama yakni Tambang Air Laya, lokasi dilakukannya penelitian ini, kemudian Muara Tiga Besar dan Banko Barat.

Tahapan penelitian dimulai dengan studi literatur dengan mencari serta mempelajari bahan pustaka yang diperoleh dari instansi terkait, buku, serta jurnal penelitian sebelumnya yang berhubungan. Tahapan selanjutnya yakni orientasi lapangan dengan mengamati keadaan yang sebenarnya di lapangan sehingga didapatkan gambaran dalam pengambilan data. Melalui tahapan ini juga diketahui aktivitas pengolahan batu andesit pada unit crushing plant di PT Bukit Asam, Tbk. Kemudian dilakukan pengambilan data yang dibutuhkan dalam penelitian. Data-data tersebut terdiri dari:

1. Data primer

Data primer ialah data yang dikumpulkan dan didapat melalui pengamatan langsung. Data ini terdiri dari:

a. Pengukuran kecepatan belt conveyor Pengukuran dilakukan dengan cara menghitung banyaknya putaran pulley pada belt conveyor dalam satu menit. hasil penambangan perlu diolah dan mengalami andesit yang dapat digunakan untuk material konstruksi, perlu dilakukan pengujian baik secara fisik maupun mekanik sehingga kualitasnya memenuhi persyaratan mutu standar Indonesia yang ditetapkan (Karim, 2019).

Gradasi atau besar butir agregat merupakan faktor yang perlu diperhatikan dalam membuat campuran beton, karena ukuran butir agregat (gradasi) yang baik akan menjadikan beton memiliki kepadatan yang tinggi dan porositas rendah (Purwati, 2014).

Batu andesit sebagai bahan bangunan dengan menggunakan analisis petrografi serta sifat keteknikan yang dimiliki batu andesit di daerah penelitian. Berdasarkan analisis tersebut, didapatkan rekomendasi dalam pemanfaatan batu andesit di daerah penelitian menurut SNI 03-0394-1989 (Ridwan, 2018) (Karim, 2019)..

Untuk mendapatkan kualitas batu andesit hasil pengolahan, perlu dilakukan pengujian agregat kasar dapat dilakukan dengan pengujian analisis ayakan. Dari uji ini akan didapatkan nilai modulus kehalusan batuan hasil pengolahan (Moniaga, 2018) (Besouw, 2019). Tujuan penelitian ini untuk menganalisis produktivitas crushing plant dalam mengelolah batu andesit sesuai dengan permintaan dan peruntukkannya.

b. Pengukuran troughing angle dan surcharge angle pada belt conveyor

Pengukurannya dilakukan dengan menggunakan aplikasi angle inclination pada smartphone, dengan menempelkan salah satu sisi smartphone pada idler dan material andesit. Besar sudut tersebut akan terbaca pada layar handphone.

c. Pengukuran panjang idler tengah dan panjang idler sayap hingga batas pengisian material dilakukan menggunakan meteran.

d. Pengukuran kemiringan belt conveyor

Pengukurannya dilakukan dengan menggunakan aplikasi angle inclination melalui batuan smartphone dengan menempelkan salah satu sisi handphone pada rangka besi belt conveyor.

e. Ukuran feed dan produk di unit crushing plant

Ukuran feed dan produk didapatkan dengan mengukur panjang, tebal serta lebar pada 33 sampel yang diambil secara acak.

f. Berat sampel hasil uji analisis ayakan Uji ayakan ini hanya dilakukan pada batu andesit yang berukuran $0-20 \mathrm{~mm}$. Proses pengujian dimulai dengan menimbang berat batu andesit terlebih dahulu. Setelah itu, siapkan satu set ayakan yang 
berurutan mulai dari pan di bagian terbawah, hingga $0,15 \mathrm{~mm}, 0,30 \mathrm{~mm}$, $0,85 \mathrm{~mm}, 1,18 \mathrm{~m}, 2,36 \mathrm{~mm}, 4,75 \mathrm{~mm}, 9,5$ $\mathrm{mm}, 12,5 \mathrm{~mm}, 19 \mathrm{~mm}, 25 \mathrm{~mm}$ dan $38 \mathrm{~mm}$ ke atas. Kemudian letakkan sampel pada ayakan teratas dan tutup. Lakukan proses ayakan selama kurang lebih 15 menit. Kemudian timbang batu andesit yang tertinggal pada tiap-tiap ukuran ayakan.

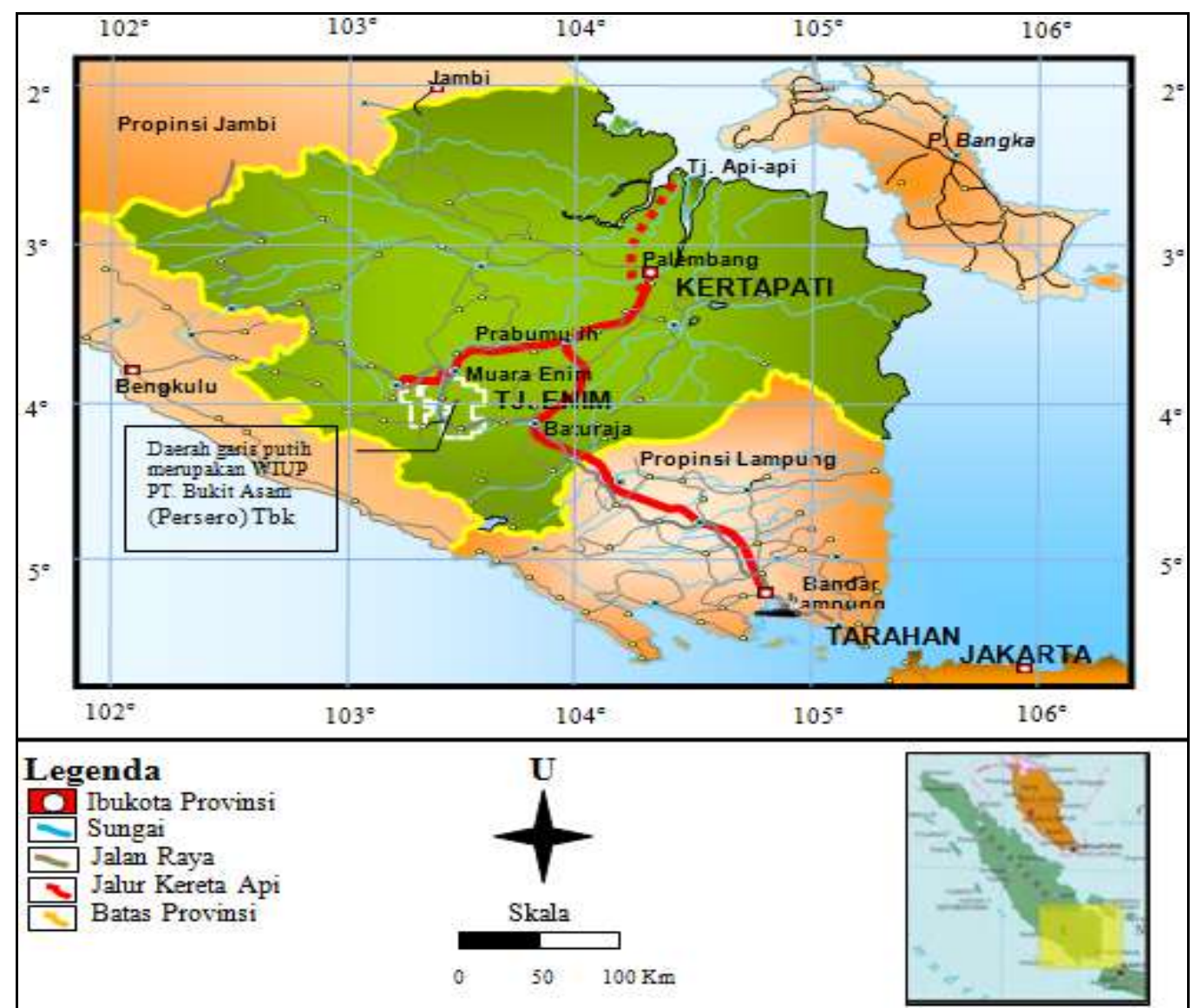

Gambar 1. Lokasi penelitian

2. Data sekunder

Data sekunder merupakan data yang diperoleh dari sumber terpercaya dan menjadi data pelengkap. Data ini meliputi:

a. Spesifikasi alat pengolahan di unit crushing plant

Spesifikasi alat dibutuhkan pada pengolahan data dalam perhitungan produktivitas aktual unit crushing plant.

b. Jam operasi crusher bulan Maret

Jam operasi ini diperlukan untuk menghitung produktivitas aktual unit crushing plant selama bulan Maret. Jam operasi ini juga digunakan untuk menilai ketersediaan alat pada unit tersebut.

c. Jumlah feed yang masuk bulan Maret Jumlah feed yang masuk diperlukan dalam menghitung material balance hasil pengolahan.

Setelah data primer dan sekunder didapatkan, maka dilakukan pengolahan data. Pengolahan data merupakan tahapan perubahan data-data yang diambil, kemudian disusun berdasarkan urutan, dihitung, dan dianalisis sebagai masukan. Tahapan pengolahan data yang dilakukan yakni:

Pertama, dilakukan perhitungan produktivitas aktual dari crushing plant. Perhitungan produktivitas unit crushing plant dapat dilakukan dengan menghitung kapasitas produksi dari belt conveyor. Komponen yang diperlukan dalam perhitungan produktivitas belt conveyor diantaranya kecepatan belt conveyor, luas penampang belt, kemiringan belt serta densitas batu andesit. Perhitungan kecepatan belt conveyor dapat menggunakan persamaan 1 berikut (Cahya, 2018):

$$
V=r \times n 2 \times 0,10472
$$

\section{Keterangan:}

$\mathrm{V}=$ kecepatan belt conveyor $(\mathrm{m} / \mathrm{s})$

$\mathrm{r}=$ jari-jari pulley $(\mathrm{m})$

$\mathrm{n} 2=$ kecepatan pulley $(\mathrm{rpm})$ 
Untuk menghitung luas penampang belt yang memiliki tiga buah idler, dapat digunakan skema (Gambar 2) berikut:

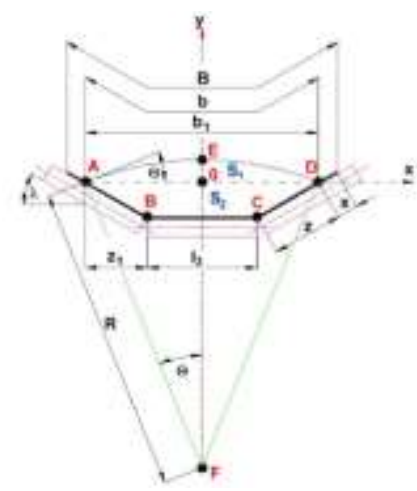

Gambar 2. Cross-section through troughed conveyor (Hrabovsky, 2011)

Berdasarkan skema di atas, beberapa variabel digunakan dalam menghitung luas penampang belt conveyor dan didapatkan persamaan 2 berikut (Hrabovsky, 2011):

$\mathrm{S}=\frac{1}{2}\left(\frac{2 \cdot z \cdot \cos \lambda+I_{3}}{2 \cdot \sin \theta}\right)^{2} \cdot\left(\frac{2 \cdot \pi \cdot \theta}{180}-\sin 2 \cdot \theta\right)+z \cdot \sin \lambda \cdot\left(I_{3}+z \cdot \cos \lambda\right)$

Keterangan:

$\mathrm{S}$ = luas penampang belt conveyor $\left(\mathrm{m}^{2}\right)$

$\mathrm{Z}$ = panjang idler sayap hingga batas pengisian material $(\mathrm{m})$

$\mathrm{I}_{3}=$ panjang idler tengah $(\mathrm{m})$

$\lambda=$ troughing angle $\left({ }^{\circ}\right)$

$\theta=$ surcharge angle $\left({ }^{\circ}\right)$

Kemiringan belt conveyor dibutuhkan untuk menentukan faktor koreksi inklinasi. Faktor ini dapat dilihat pada tabel berikut:

Tabel 1. Tabel faktor koreksi untuk inclined or falling transport (Putri, 2018)

\begin{tabular}{cc}
\hline$\varphi\left(^{o}\right)$ & $\mathbf{k}$ \\
\hline $\mathbf{2}$ & 1 \\
\hline $\mathbf{4}$ & 0,99 \\
\hline $\mathbf{6}$ & 0,98 \\
\hline $\mathbf{8}$ & 0,97 \\
\hline $\mathbf{1 0}$ & 0,95 \\
\hline $\mathbf{1 2}$ & 0,93 \\
\hline $\mathbf{1 4}$ & 0,91 \\
\hline $\mathbf{1 6}$ & 0,89 \\
\hline $\mathbf{1 8}$ & 0,85 \\
\hline $\mathbf{2 0}$ & 0,81 \\
\hline $\mathbf{2 2}$ & 0,76 \\
\hline
\end{tabular}

Keterangan: $\varphi=$ kemiringan belt conveyor $\left({ }^{\circ}\right) ; \mathrm{k}$ $=$ faktor koreksi inklinasi
Untuk menghitung kapasitas produksi dari belt conveyor dapat digunakan pers. (3) berikut [10]:

$\mathrm{Q}=S \times v \times \gamma \times \mathrm{k} \times 3600$

Keterangan:

$\mathrm{Q}=$ kapasitas produksi belt conveyor (ton/jam)

$\mathrm{S}=$ luas penampang belt conveyor $\left(\mathrm{m}^{2}\right)$

$v=$ kecepatan belt $(\mathrm{m} / \mathrm{s})$

$\mathrm{Y}=$ bulk density $\left(\right.$ ton $\left./ \mathrm{m}^{3}\right)$

$\mathrm{k}=$ faktor koreksi inklinasi

Tahapan selanjutnya diilakukan perhitungan nilai ketersediaan alat. Nilai kesediaan ini akan menunjukkan kinerja alat mekanis. Ketersediaan alat juga mempengaruhi produktivitas crusher dipengaruhi jam kerja. Nilai ketersediaan alat terdiri dari:

1. Ketersediaan Mekanis (MA)

Perhitungan ketersediaan mekanis dinyatakan dengan pers. (4):

$\mathrm{MA}=\frac{W}{W+R} \times 100 \%$

2. Ketersediaan Fisik (PA)

Perhitungan ketersediaan fisik dinyatakan dengan pers. (5):

$\mathrm{PA}=\frac{W+s}{W+R+s} \times 100 \%$

3. Ketersediaan Penggunaan (UA)

Perhitungan ketersediaan penggunaaa dinyatakan dengan pers. (6):

$\mathrm{UA}=\frac{W}{W+S} \times 100 \%$

4. Penggunaan Efektif (EU)

Perhitungan penggunaan efektif dinyatakan dengan pers. (7):

$\mathrm{EU}=\frac{W}{W+R+S} \times 100 \%$

Keterangan:

$\mathrm{W}=$ waktu kerja (working hours) (Jam)

$\mathrm{R}=$ waktu perbaikan (repair hours) (Jam)

$\mathrm{S}=$ waktu menunggu (standby hours) (Jam)

Kategori penilaian terhadap ketersediaan alat mekanis, dibagi menjadi 4 yaitu, baik sekali antara $83-92 \%$, sedang berkisar $75-83 \%$, kurang baik antara $64-75 \%$ sedangkan buruk apabila kurang dari $64 \%$ (Susanto, 2019).

Dalam menentukan kualitas batu andesit di PT Bukit Asam Tbk. perlu diketahui reduction ratio. Semakin besar nilai reduction ratio maka semakin beragam dan semakin besar hasil pengolahan. Perhitungan nilai reduction ratio 
dapat menggunakan pers. (8) berikut (Ramadani, 2017):

Reduction ratio $=\frac{\text { Ukuran rata }- \text { rata } \text { feed }}{\text { Ukuran rata-rata produk }}$

Setelah itu lakukan analisis neraca bahan (material balance). Analisis neraca bahan digunakan untuk menghitung persentase losses pengolahan yang menyatakan baik atau buruk hasil pengolahan pada unit crushing plant. Perhitungan material balance dapat menggunakan pers. (9) berikut:

$F=P+L$

Keterangan:

$\mathrm{F}=$ bobot umpan (ton/jam atau \%)

$\mathrm{P}=$ produk yang dihasilkan (ton/jam atau \%)

$\mathrm{L}$ = banyaknya material yang hilang (ton/jam atau \%)
Agar diketahui kualitas batu andesit hasil pengolahan di PT Bukit Asam, Tbk. memenuhi standar sebagai bahan baku campuran beton atau tidak, dilakukanlah uji analisis ayakan. Setelah uji ayakan, dilakukan perhitungan nilai modulus kehalusan. Nilai modulus kehalusan (Mh) didapatkan dengan menjumlahkan berat kumulatif sampel yang tertinggal pada tiap-tiap ayakan, kemudian menggunakan pers. (10) berikut:

$M h=\frac{\text { persen berat kumulatif tertinggal }-100}{100}$

Nilai modulus kehalusan yang didapatkan dari uji ayakan harus kembali dianalisis dan dibandingkan dengan ketetapan modulus kehalusan yang sesuai SNI yang berkisar antara 6-7,10.

Untuk memenuhi kualitas mutu baku beton, agregat kasar yang diuji melalui uji ayakan harus menunjukkan gradasi yang sesuai dengan standar pada Tabel 2 berikut:

Tabel 2. Gradasi agregat kasar

\begin{tabular}{|c|c|c|c|c|c|c|}
\hline \multirow{2}{*}{\multicolumn{4}{|c|}{$\begin{array}{l}\text { Ukuran Saringan } \\
\text { Ayakan }\end{array}$}} & \multicolumn{3}{|c|}{ \% Lolos Saringan / ayakan } \\
\hline & & & & \multirow{2}{*}{$\begin{array}{l}\text { Ukuran } \\
\text { Maks. } 10 \\
\mathrm{~mm}\end{array}$} & \multirow{2}{*}{$\begin{array}{l}\text { Ukuran } \\
\text { Maks. } 20 \\
\mathrm{~mm}\end{array}$} & \multirow{2}{*}{$\begin{array}{l}\text { Ukuran } \\
\text { Maks. } 40 \\
\mathrm{~mm}\end{array}$} \\
\hline $\mathrm{mm}$ & SNI & ASTM & Inchi & & & \\
\hline 75,0 & 76 & 3 in & 3,00 & & & $100-100$ \\
\hline 37,5 & 38 & $1 \frac{1}{2}$ in & 1,50 & & $100-100$ & $95-100$ \\
\hline 19,0 & 19 & $3 / 4$ in & 0,75 & $100-100$ & $95-100$ & $35-70$ \\
\hline 9,5 & 9,6 & $3 / 8$ in & 0,3750 & $50-85$ & $30-60$ & $10-40$ \\
\hline 4,75 & 4,8 & No.4 & 0,1870 & $0-10$ & $0-10$ & $0-5$ \\
\hline
\end{tabular}

Keterangan: mm (milimeter); SNI (standar nasional Indonesia); ASTM (American standard testing material)

\section{Hasil dan Pembahasan}

Penambangan batu andesit dilakukan dengan metode penambangan quarry, dengan terlebih dahulu melakukan pemberaian batu andesit secara mekanis dengan menggunakan metode peledakan.

Proses pengolahan batu andesit di PT Bukit Asam Tbk. pada unit crushing plant dimulai ketika dump truck yang membawa material dari quarry menumpahkan bawaannya ke dalam penampungan sementara. Material yang siap diolah akan diumpankan feeder ke dalam jaw crusher untuk dilakukan proses penghancuran. Proses penghancuran yang dilakukan oleh jaw crusher merupakan proses reduksi ukuran boulder batu andesit hasil peledakan yang berukuran $700 \mathrm{~mm}$, menjadi beberapa ukuran yang dibutuhkan oleh PT Bukit Asam, Tbk. Proses ini dilakukan menyerupai pabrik atau crushing plant (Gambar 3).

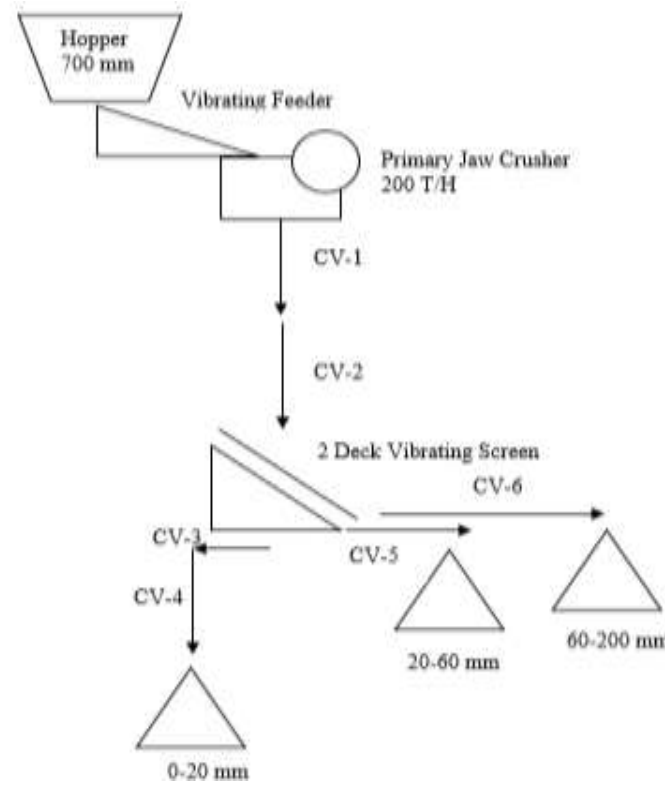

Gambar 3. Alur pengolahan batu andesit PT Bukit Asam, Tbk. 
Berdasarkan alur di atas, terdapat beberapa komponen pada crushing plant yang berkerja secara berkesinambungan. Komponen unit crushing plant PT Bukit Asam, Tbk sebagai berikut:

1. Hopper

Material yang siap untuk diolah berada di dalam hopper. Agar diketahui kapasitas dari hopper di unit crushing plant andesit PT Bukit Asam, Tbk. dilakukan pengukuran langsung dimensi dari hopper tersebut. Berikut tabel 3 di bawah ini yang menunjukkan dimensi hopper: Kapasitas hopper yang ada pada unit crushing plant sebesar $32,665 \mathrm{~m}^{3}$. Agar kapasitas hopper tersebut terpenuhi, dibutuhkan 8 kali ritase dump truck yang memiliki kapasitas $4 \mathrm{~m}^{3}$.

Tabel 3. Data ukuran dimensi hopper

\begin{tabular}{lc}
\hline \multicolumn{2}{c}{ Dimensi Hopper } \\
\hline Panjang Atas $(\mathrm{m})$ & $6,20 \mathrm{~m}$ \\
\hline Lebar Atas $(\mathrm{m})$ & $5,04 \mathrm{~m}$ \\
\hline $\begin{array}{l}\text { Panjang Bawah } \\
(\mathrm{m})\end{array}$ & $1,17 \mathrm{~m}$ \\
\hline Lebar Bawah $(\mathrm{m})$ & $2,70 \mathrm{~m}$ \\
\hline Ketinggian $(\mathrm{h})(\mathrm{m})$ & $2,21 \mathrm{~m}$ \\
\hline Luas Atas $\left(\mathrm{m}^{2}\right)$ & $31,248 \mathrm{~m}^{2}$ \\
\hline Luas Bawah $\left(\mathrm{m}^{2}\right)$ & $3,159 \mathrm{~m}^{2}$ \\
\hline
\end{tabular}

2. Vibrating feeder

Feeder akan memberikan pengumpanan pada jaw crusher secara teratur dan juga terus menerus. Dalam proses pengumpanannya, vibrating feeder akan bergetar dan membuat material dari hopper

Produktivitas aktual unit crushing plant perlu diketahui agar produksi yang ditargetkan oleh perusahaan sebesar 200 ton/jam tercapai atau tidak. Produktivitas unit crushing plant dapat diketahui dengan melakukan perhitungan menggunakan persamaan kapasitas produksi dari belt conveyor. Dalam perhitungannya, jatuh dan masuk secara teratur ke dalam jaw crusher.

3. Jaw Crusher

Batuan akan dikenakan gaya tekan oleh jaw crusher yang akan mengakibatkan batuan dapat hancur dan terpecah. Pemecahan menggunakan jaw crusher tidaklah seragam. Jaw crusher yang ada di unit crushing plant ini, menjadi alat utama dalam melakukan proses peremukan.

\section{Belt Conveyor}

Belt conveyor yang ada pada unit crushing plant di PT Bukit Asam, Tbk terdiri dari 6 buah unit instalasi conveyor. Belt conveyor 1 akan menyalurkan batu andesit langsung dari jaw crusher menuju transfer belt conveyor 2 yang mengarah ke vibrating screen. Pada vibrating screen batu andesit akan terpisah sesuai fraksi yang telah diatur. Batu andesit yang berukuran 0-20 mm, akan menuju stockpile batu 20 melalui belt conveyor 3 dan melalui transfer belt conveyor 4 terlebih dahulu. Batu andesit yang berukuran 20-60 mm, akan dibawa menuju stockpile batu 60 melalui belt conveyor 5 . Sedangkan batu andesit yang berukuran $60-200 \mathrm{~mm}$, akan disalurkan oleh belt conveyor 6 menuju stockpile batu 200 .

\section{Vibrating Screen}

Ketika umpan masuk ke dalam vibrating screen, alat tersebut akan bergetar dan mengakibatkan material yang dapat lolos dari ayakan pertama akan jatuh menuju ayakan kedua, dan tahapan tersebut berlanjut sampai ayakan terakhir.

dibutuhkan kecepatan belt conveyor, luas penampang belt conveyor, kemiringan belt conveyor, serta densitas material yang diangkut dengan rekapitulasi nilai kecepatan masingmasing belt conveyor ditunjukkan pada Tabel 4 berikut:

Tabel 4. Rekapitulasi kecepatan belt conveyor

\begin{tabular}{llll}
\hline $\begin{array}{l}\text { Unit Belt } \\
\text { Conveyor }\end{array}$ & $\mathbf{v}(\mathbf{m} / \mathbf{s})$ & $\mathbf{A}\left(\mathbf{m}^{2}\right)$ & $\begin{array}{c}\text { Produktivitas } \\
\text { Belt Conveyor } \\
\text { (Ton/Jam) }\end{array}$ \\
\hline CV-1 & 1,676829 & 0,012 & 147,3991 \\
CV-2 & 1,724738 & 0,010 & 146,0267 \\
CV-3 & 1,658765 & 0,001 & 18,2631 \\
CV-4 & 1,708769 & 0,001 & 17,8585 \\
CV-5 & 1,658765 & 0,002 & 27,0768 \\
CV-6 & 1,639915 & 0,007 & 97,2332 \\
\hline
\end{tabular}


Kapasitas produksi unit crushing plant berasal dari unit belt conveyor CV-4, CV-5 dan CV-6, sehingga didapatkan produksi aktual unit crushing plant sebesar 142,1685 ton/jam. Tidak tercapainya target produksi yang dibuat perusahaan dipengaruhi oleh banyak hal, diantaranya kemampuan alat tersebut. Kemampuan alat dapat diketahui dengan melakukan perhitungan nilai ketersediaan alat.
Pada bulan Maret, waktu kerja yang tersedia di unit crushing plant adalah 341 jam/bulan. Akan tetapi, pekerjaan produksi hanya dilakukan selama 98,5 jam. Waktu standby alat selama 105,5 jam dan perbaikan selam 137 jam. Nilai ketersediaan alat di unit crushing plant ditunjukkan pada Tabel 5 berikut:

Tabel 5. Nilai ketersediaan alat

\begin{tabular}{lllll}
\hline $\begin{array}{c}\text { Ketersedi } \\
\text { aan Alat }\end{array}$ & MA & PA & UA & \multicolumn{1}{c}{ EU } \\
\hline Nilai & $\begin{array}{l}41,83 \\
\%\end{array}$ & $\begin{array}{l}59,82 \\
\%\end{array}$ & $\begin{array}{l}48,2 \\
8 \%\end{array}$ & $\begin{array}{l}28,89 \\
\%\end{array}$ \\
\hline
\end{tabular}

Nilai ketersediaan alat menunjukkan angka < $64 \%$, sehingga kinerja alat pada unit crushing plant dikatakan buruk. Nilai ketersediaan yang kecil menyebabkan kecilnya kemungkinan untuk dapat mencapai produksi yang ditargetkan. Nilai ketersediaan alat yang buruk, dapat diketahui bahwa produksi aktual unit crushing plant sebesar 134,9132 ton/jam merupakan produksi maksimal unit ini.

Pada bulan Maret, unit crushing plant hanya bekerja selama 98,5 jam dengan efisiensi kerja sebesar $28,89 \%$. Maka, produktivitas aktual unit crushing plant untuk bulan Maret adalah 13.288,99 ton/bulan. Ukuran produk yang dihasilkan dari proses pengolahan berhubungan dengan nilai reduction ratio pada crusher. Jaw crusher diatur agar mampu menerima umpan maksimum $700 \mathrm{~mm}$ dan diharapkan dapat menghasilkan ukuran produk sebesar $\pm 200 \mathrm{~mm}$. Nilai reduction ratio teoretis alat jaw crusher sebesar 3,5. Sedangkan berdasarkan pengukuran, didaptkan ukuran umpan yang masuk sebesar $51,25 \mathrm{~cm}$ dan hasil reduksi sebesar $8,87 \mathrm{~cm}$.

Nilai reduction ratio aktual sebesar 4,137. Nilai reduction ratio aktual yang lebih besar daripada nilai reduction ratio teoritis menunjukkan bahwa produk pengolahan sangat beragam dan memiliki butir gradasi yang besar. Jumlah umpan yang masuk pada unit crushing plant untuk bulan Maret sebanyak 147,125 ton/jam dengan produk yang dihasilkan sebesar 142,1685 ton/jam. Nilai looses sebanyak 5,9565 ton/jam dan persentase looses material dan persentase produk sebesar $95,98 \%$. Nilai losses material sebanyak 5,9565 ton/jam terjadi pada beberapa tahapan pengolahan.

Kehilangan material terjadi pada tahapan pemindahan material dari satu unit ke unit lainnya. Berdasarkan tabel 6 , dapat diketahui kehilangan material hasil pengolahan dari tiaptiap proses pengolahan. Umpan yang masuk sebanyak 147,125 ton/jam mengalami reduksi ukuran di dalam jaw crusher. Material yang di transportasikan belt conveyor 1 sebanyak 147,3991 ton/jam, sehingga pada tahapan crushing terjadi kehilangan material sebanyak 0,7259 ton/jam. Kehilangan ini berupa debu, kondisi di sekitar jaw crusher sering tertutup debu. Selain itu, kehilangan ini terjadi pada disekitar jaw crusher dan belt-conveyor.

Pada belt conveyor 1 dan belt conveyor 2 juga terjadi losses sebesar 1,3724 ton/jam. Lossses ini terjadi akibat posisi penempatan belt conveyor yang kurang tepat menyebabkan material terkadang jatuh tidak tepat diatas belt conveyor 2 . Sehingga material dari belt conveyor 1 ke belt conveyor 2 hanya tertransportasi sebesar 146,0267 ton/jam.

Pada tahapan sizing, kehilangan material cukup besar. Material batu andesit berukuran 60$200 \mathrm{~mm}$ merupakan material terbanyak, sehingga material ini sering terlempar keluar. Kehilangan pada tahapan ini sebanyak 3,4537 ton/jam. Selain itu, losses terjadi pada proses transfer material dari belt conveyor 3 ke belt conveyor 4.

Material yang didistribusikan pada tahapan berukuran kecil, sehingga losses yang terjadi berupa debu. Kehilangan material pada tahapan ini sebanyak 0,04045 ton/jam. Dari hasil perhitungan neraca bahan di atas, persentase produk cukup besar, yakni >90\%. Hal ini menunjukkan bahwa kinerja unit crushing plant yang baik dalam melakukan proses reduksi ukuran dan menghasilkan produk pengolahan yang memungkinkan untuk dapat dipasarkan.

Sampel yang dipakai pada uji analisis ayakan merupakan sampel yang berasal dari batu andesit hasil pengolahan yang berukuran $0-20$ $\mathrm{mm}$. Berat sampel awal yang digunakan ialah 2.800 gram dan meninggalkan 2.794,2 gram sampel setelahnya. Hal ini menunjukkan bahwa terjadi losses selama proses pengayakan berlangsung sebanyak 55,8 gram. 
Berdasarkan hasil uji ayakan, didapatkan berat batu andesit yang tertinggal pada tiap-tiap ukuran ayakan (Tabel 6).

Tabel 6. Analisis data uji ayakan

\begin{tabular}{|c|c|c|c|c|c|}
\hline \multirow{2}{*}{$\begin{array}{c}\text { Ukuran } \\
\text { Ayakan } \\
(\mathrm{mm})\end{array}$} & \multicolumn{3}{|c|}{ Batuan yang Tertinggal } & \multirow{2}{*}{$\begin{array}{c}\text { Berat } \\
\text { Lolos } \\
\text { Kumulatif } \\
(\%)\end{array}$} & \multirow{2}{*}{$\begin{array}{c}\text { \% Lolos } \\
\text { SNI }\end{array}$} \\
\hline & gram & $\%$ & $\begin{array}{c}\text { Persen } \\
\text { Kumulatif }\end{array}$ & & \\
\hline 38,10 & & 0,00 & 0,00 & 100,00 & $100-100$ \\
\hline 25,40 & 0,0 & 0,00 & 0,00 & 100,00 & - \\
\hline 19,00 & 43,7 & 1,56 & 1,56 & 98,44 & $95-100$ \\
\hline 12,70 & $2.108,6$ & 75,46 & 77,03 & 22,97 & - \\
\hline 9,50 & 413,2 & 14,79 & 91,82 & 8,18 & $30-60$ \\
\hline 4,75 & 203,3 & 7,28 & 99,09 & 0,91 & $0-10$ \\
\hline 2,36 & 7,8 & 0,28 & 99,37 & 0,63 & - \\
\hline 1,18 & 0,0 & 0,00 & 99,37 & 0,63 & - \\
\hline 0,85 & 0,0 & 0,00 & 99,37 & 0,63 & - \\
\hline 0,30 & 0,0 & 0,00 & 99,37 & 0,63 & - \\
\hline 0,15 & 2,3 & 0,08 & 99,45 & 0,55 & - \\
\hline $\begin{array}{l}0,00 \\
\text { (Pan) }\end{array}$ & 15,3 & 0,55 & 100,00 & 0,00 & - \\
\hline Total & $2.794,2$ & 100 & 866,43 & 333,57 & - \\
\hline
\end{tabular}

Pada ayakan berukuran $9,50 \mathrm{~mm}$, persentase berat lolos kumulatif sebesar $8,18 \%$ belum memenuhi persen lolos sesuai dengan standar nasional Indonesia yakni $30-60 \%$ dari berat sampel. Hal ini disebabkan $22,97 \%$ berat sampel tertahan pada ayakan ini, sehingga untuk memenuhi persyaratan persentase yang ditetapkan, diperlukan batu andesit yang berukuran lebih kecil dari ukuran ayakan 9,50 $\mathrm{mm}$.

Jumlah keseluruhan persen kumulatif berat sampel batu andesit yang tertinggal adalah $866,43 \%$ dengan nilai modulus kehalusan sebesar 7,66. Nilai ini menunjukkan belum terpenuhinya modulus kehalusan yang sesuai standar nasional Indonesia maupun standar industri Indonesia yang bersyarat dalam rentang 6-7,10. Untuk memenuhi persyaratan tersebut, maka diperlukan material yang memiliki gradasi yang lebih kecil dari sampel yang diayak. Diperlukan juga tahapan pengolahan lanjutan menggunakan secondary crusher agar batu andesit hasil pengolahan lebih seragam.

\section{Kesimpulan}

Pengolahan batu andesit di PT Bukit Asam, Tbk menghasilkan 3 produk ukuran yakni batu 200 , batu 60 dan batu 20 atau split. Nilai modulus kehalusan memiliki nilai 7,66 sehingga perlu adanya tahapan pengolahan lanjutan agar hasil pengolahan lebih seragam sesuai dengan SNI.

\section{Ucapan Terimakasih}

Penulis mengucapkan terima kasih kepada bapak Ir. Mukiat, M.S. yang sudah memberikan ide serta gagasan untuk penelitian ini.

\section{Daftar Pustaka}

Besouw, G. V., Manoppo, M. R. E. dan Palenewen, S. C. N., (2019). Pengaruh Modulus Kehalusan Agregat terhadap Penentuan Kadar Aspal pada Campuran Jenis AC-WC, Jurnal Sipil Statik, 7(4): 483489.

Cahya, R. N., Hasjim, M. dan Ningsih Y.B., (2020). Kajian Kinerja Unit Crushing Plant Batu Andesit PT Sumber Gunung Maju, Jurnal Pertambangan, 4(1): 28-30.

Hrabovsky, L., (2011). Cross-Sectional Area of The Belt Conveyor with A Three-Idler Set, VI (III), 63-67.

Karim, R. dan Suriadi, S., (2019). Kajian Karakteristik Batuan Beku Andesit sebagai Bahan Bangunan di Daerah Sulamadaha Kecamatan Ternate Barat Kota Ternate, Dintek, 12 (2), 3-8.

Moniaga, F., (2018). Evaluasi Penggunaan Material Agregat Kasar Parameter Dia 10-20 $\mathrm{mm}$ dan 5-10 mm pada Campuran Beton Lapangan dengan Specified Characteristic Strength. Jurnal Realtech. 14(1). 92-95.

Nugraha, S., Widayati, S. dan Yuliadi, (2018). Upaya Peningkatan Produksi (Split) Batu Andesit dengan Metode Perubahan CSS (Closed Side Setting) pada Crushing Plant di 
PT Panghear Mitra Abadi Desa Lagadar, Kecamatan Margaasih, Kabupaten Bandung, Provinsi Jawa Barat, Prosiding Teknik Pertambangan, Bandung: Fakultas Teknik.

Purwati, A, As'ad, S. dan Sunarmasto, (2014). Pengaruh Ukuran Butiran Agregat Terhadap Kuat Tekan dan Modulus Elastisitas Beton Kinerja Tinggi Grade 80. E-Jurnal Matriks Teknik Sipil. 2(2): 58-63.

Putra, R.S., Pulungan, L. dan Muchsin, A.M., (2018). Evaluasi Kinerja Unit Alat Peremuk (Crusher) Batuan Andesit di PT Sinar Mandiri Mitrasejati, Desa Rengasjajar, Kecamatan Cigudeg, Kabupaten Bogor, Provinsi Jawa Barat, Prosiding Teknik Pertambangan, Bandung: Fakultas Teknik.

Putri, F. E. dan Abdullah, R., (2018). Kajian Teknis Produktivitas dan Efisiensi dalam Pengiriman Limestone \& Silicastone ke Storage Indarung pada PT Semen Padang Sumatera Barat, Jurnal Bina Tambang, 3(3): 1080-1088.
Ramadani, B., Komar, S. dan Ningsih, Y. B. (2017). Evaluasi Kinerja Unit Crushing Plant pada Tambang Andesit untuk Mencapai Target Produksi 800 ton/bulan pada Bulan Mei 2016 di PT Ansar Terang Crushindo Kabupaten Limapuluh Kota Sumatra Barat. Jurnal Pertambangan. 1(3).

Ridwan, P., Arfiansyah, K., Kusumah, P. A., Amrullah, F., dan Gani, R M. G., (2018). Identifikasi Karakteristik dan Kualitas Andesit sebagai bahan bangunan daerah batujajar, Kecamatan Batujajar Timur, Kabupaten Bandung Barat. Padjajaran Geoscience Journal, 2(3), 194-199.

Susanto, D. P. R., (2019). Kajian Teknis Produktivitas Unit Peremukan Batu Andesit di PT Gawi Maju Kabupaten Purworejo Provinsi Jawa Tengah. Skripsi, Teknik Pertambangan: Universitas Pembangunan Nasional "Veteran" Yogyakarta. 